\title{
FLORAL NEIGHBORHOOD AND POLLINATION SUCCESS IN FOUR HUMMINGBIRD-POLLINATED CLOUD FOREST PLANT SPECIES ${ }^{1}$
}

\author{
Peter Feinsinger, K. Greg Murray, Sharon Kinsman, ${ }^{2}$ and \\ WILLIAM H. BUSBY \\ Department of Zoology, University of Florida, Gainesville, Florida 32611 USA
}

\begin{abstract}
In a cloud forest at Monteverde, Costa Rica, we examined pollen loads received by self-compatible flowers of two pairs of plant species pollinated by hummingbirds: Hansteinia blepharorachis and Razisea spicata (Acanthaceae), and Besleria triflora and Drymonia rubra (Gesneriaceae). Each pair consisted of one species (Hansteinia or Besleria) pollinated by short-billed hummingbirds and a related species (Razisea or Drymonia) pollinated by long-billed hummingbirds. At three different times per species, separated by 1-3 mo, we examined flowers on 28-40 focal plants from a wide variety of floral neighborhoods, ranging from plants isolated from conspecifics, either by distance or by other flowering species pollinated by the same hummingbirds, to plants surrounded by conspecifics.

Because short-billed hummingbirds often restrict foraging to areas of high flower density, and because short-tubed flowers adapted for hummingbirds often have similar pollen placement, we predicted that short-tubed flowers isolated from conspecifics would receive fewer conspecific grains and more heterospecific grains than short-tubed flowers surrounded by conspecifics. Because long-billed hummingbirds often forage over large areas and because long-tubed flowers adapted for hummingbirds tend to diverge in pollen placement, we predicted that pollination of long-tubed flowers would be relatively unaffected by floral neighborhood.

Effects on pollen loads of floral neighborhood (nearness to or isolation from other flowers) followed few patterns consistent with our prediction or with conventional theory. (1) There were no consistent effects of floral neighborhoods on numbers of heterospecific grains deposited on stigmas; in all four species, regardless of corolla length, effects of particular neighborhood variables (as determined with stepwise multiple regression) were as likely to run exactly counter to conventional models as to corroborate models. (2) In none of the 12 sampling runs did increases in absolute densities of neighboring heterospecific flowers adversely affect pollination. (3) However, in two runs, loads of conspecific grains increased with increases in the absolute density of neighboring conspecific flowers, and/or (in three runs) with increases in their relative density (proportion of conspecifics among neighboring flowers). These runs all involved short-flowered species rather than long-flowered species, tending to confirm our initial prediction, but half the sampling runs, even of short-flowered species, failed to show any density-dependent effects from neighboring flowers pollinated by the same hummingbirds.

Flowers frequently received fewer conspecific grains than they had ovules to be fertilized. Therefore, the potential existed for floral neighborhoods to affect seed set and fitness of plants. Nevertheless, even though neotropical hummingbird-pollinated flowers have been cited as examples of species whose flowering peaks are displaced through competition for pollination, competitive effects from neighboring heterospecific plants were only sporadic in the species we examined, and were particularly infrequent in those species with long flowers adapted for long-billed hummingbirds.
\end{abstract}

Key words: cloud forest; competition; Costa Rica; facilitation; hummingbirds; pollen; phenology.

\section{INTRODUCTION}

In natural populations of plants, some individuals are situated near conspecifics and others are isolated. Just as isolation can affect herbivory (Evans 1983) and frugivory (Manasse and Howe 1983), so can the extent and type of isolation influence pollination (Rathcke 1983, Thomson 1983, Waser 1983). First, a plant may be distant from the nearest conspecific, relative to pollinators' typical flights, or isolated in the absolute sense. Plants isolated by physical distance may experience

\footnotetext{
1 Manuscript received 22 October 1984; revised 8 May 1985; accepted 17 May 1985; final version received 21 June 1985.

${ }^{2}$ Present address: Department of Biology, Bates College, Lewiston, Maine 04240 USA.
}

low pollination success because they attract few visitors (e.g., see Augspurger 1980, 1981, Thomson 1983). Second, a plant may be isolated from conspecifics by intervening plants of different species but sharing the same pollinators (i.e., belonging to the same pollination guild), or isolated in the relative sense. Plants isolated in the relative sense, with many heterospecifics as neighbors, may experience low pollination success because visitors are apt to deposit fewer pollen grains from compatible mates, and more from other plant species, than visitors to plants surrounded by conspecifics (Waser 1978a, b, 1983, Pleasants 1983, Rathcke 1983, Thomson 1983, Campbell and Motten 1985).

If floral neighborhoods affect the pollen loads flowers receive, the number and quality of offspring per flower 
may also be affected. Where stigmas receive fewer compatible grains than there are ovules to be fertilized, fecundity drops off rapidly with decreasing numbers of grains, even if every grain fertilizes an ovule (e.g., Silander and Primack 1978, McDade and Davidar 1984). In some species, fruits with few fertilized ovules may be aborted entirely if maternal resources are limited (Stephenson 1981, Bertin 1982). Furthermore, reproductive output of flowers may benefit from loads of compatible grains that exceed the number of ovules to be fertilized, for at least two reasons: (1) full seed set may require more than one grain per ovule (Cruden 1977, Snow 1982, McDade 1983); and (2) with large numbers of pollen grains, especially if these come from several fathers (Schemske and Pautler 1984), competition among pollen tubes may increase the fitness of the ovule parent through increases in vigor and reproductive output of the resultant seeds (Mulcahy 1983, Mulcahy and Mulcahy 1983, Mulcahy et al. 1983). On the other hand, increasing numbers of heterospecific pollen grains on stigmas could reduce floral fecundity (Waser 1978b, 1983, Brown and Kodric-Brown 1979, Rathcke 1983), by “clogging” stigmas (Waser 1978b) or by exerting allelopathic effects on compatible grains (Sukhada and Jayachandra 1980, Thomson et al. 1981).

It follows that relative isolation, at least, could lead to competition among plant species, if neighboring plants reduce the number of compatible grains and increase the number of heterospecific grains deposited on one another's stigmas (Levin and Anderson 1970, Straw 1972, Bobisud and Neuhaus 1975, Wissel 1977, Waser 1978a, b, 1983, Thomson 1983, Campbell $1985 b$, Campbell and Motten 1985). A thriving debate exists over competition and its possible selective effects on flowering phenologies (reviewed by Waser 1978a, $b, 1983$, Gleeson 1981, Pleasants 1983, Rathcke 1983, 1984). Nevertheless, few studies detail the presumed mechanism through which competition operates: the effects of isolation on pollination of flowers in natural populations (although see Campbell 1985a, $b$, Campbell and Motten 1985).

In this paper we report on the effects of isolation on pollen loads received by flowers of representative species in two distinct, sympatric guilds of plants pollinated by hummingbirds. A priori, we had expected one guild to fit the conventional pattern that pollen loads suffer from isolation, and the other guild to be less affected by isolation. The setting is an undisturbed tropical forest with a full natural complement of plants and pollinators and a near absence of exotic species. We show that the results of our year-long study, while confirming our predictions in part, are far more complex than intuition or simple models might suggest, and we conclude by pointing out that relative or absolute isolation of flowers should not automatically be assumed to have consistent effects on pollination in any plant-pollinator system.

\section{Site ANd Species Studied}

The Monteverde Cloud Forest Reserve, near Monteverde, Provincia de Puntarenas, Costa Rica, is a 4000ha tract composed chiefly of pristine Lower Montane Rain Forest (Holdridge 1967). The Reserve is continuous with much larger expanses of similar forest on the crest and Atlantic slope of the Cordillera de Tilarán. While measurable precipitation decreases from December through May, the luxuriant vegetation in the cloud forest is nearly constantly wetted by mist blown over the continental divide by the prevailing northeasterly trade winds (Lawton and Dryer 1980). Therefore, sufficient moisture exists year-round for plants' vegetative growth and flowering.

From June 1981 to July 1982, we and our colleagues studied the relationship of plant-hummingbird interactions to secondary succession in the Monteverde Cloud Forest. We examined floral morphologies, breeding systems, patterns of nectar secretion, and flowering phenologies of bird-visited plant species on 14 study plots totalling 1.75 ha. We removed pollen loads from bills and feathers of mist-netted hummingbirds. We also determined the frequency with which hummingbirds and other birds visited the flowers of each plant species, tallying 12814 flower-visits during 4218 plant-hours of observation.

At Monteverde, as elsewhere in the neotropics (Feinsinger and Colwell 1978, Stiles 1981, Feinsinger 1983), two distinct kinds of interactions occurred between hummingbirds and plants. Short flowers, defined as those adapted for bird pollination and having corolla lengths of $<25 \mathrm{~mm}$, received legitimate (potentially pollinating) visits almost exclusively from hummingbirds with correspondingly short bills $(<25 \mathrm{~mm}$ total culmen length). Long flowers, or those with corolla lengths of at least $30 \mathrm{~mm}$, received legitimate visits primarily from hummingbirds with correspondingly long, often curved, bills ( $>28 \mathrm{~mm}$ total culmen). Although we observed 11 hummingbird species foraging at flowers, two were of primary importance. Males and females of the Purple-throated Mountain-gem (Lampornis calolaema, Fig. 1), with culmens $23 \mathrm{~mm}$ long, made $96.9 \%$ of the legitimate visits to short flowers. Green Hermits (Phaethornis guy, Fig. 1), with culmens $47 \mathrm{~mm}$ (males) or $46 \mathrm{~mm}$ (females) long, made $68.2 \%$ of the legitimate visits to long flowers. Most of the remaining legitimate visits to long flowers were made by Campylopterus hemileucurus, Heliodoxa jacula, and Doryfera ludovicae; fewer than $5 \%$ came from $L$. calolaema.

Both pollination guilds had similar species richness. Twenty-five species of long-flowered plants and 24 species of short-flowered plants grew on or near our cloud forest study plots. At least five species of plants apparently adapted for insect pollination also attracted, and deposited pollen on, short-billed hummingbirds. Each guild contained not only several species in the 
HUMMINGBIRDS

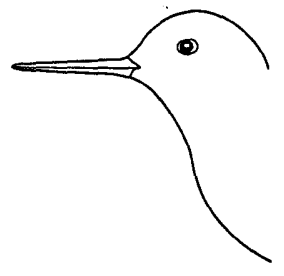

Lampornis calolaema

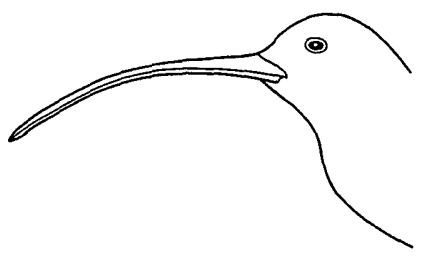

Phaethornis guy

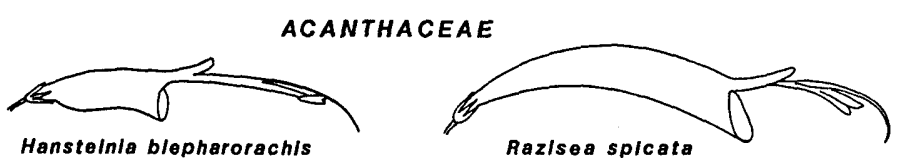

Hansteinla blepharorach/s

Razlsea splcata

\section{GESNERIACEAE}

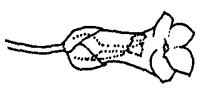

Besleria triflora
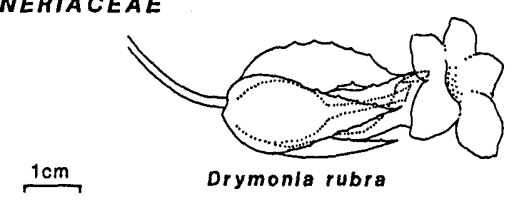

FIG. 1. Flowers of the four plant species investigated in this study, and their principal hummingbird pollinators: Lampornis calolaema, pollinator of most plants in the short-flowered guild, and Phaethornis guy, pollinator of most plants in the longflowered guild.

families Gesneriaceae and Acanthaceae, but also species from many other plant families. The major taxonomic difference between the two guilds was the high density and diversity (seven species) of epiphytic shrubs in the family Ericaceae belonging to the short-flowered guild, vs. a single, uncommon epiphytic ericad in the longflowered guild.

\section{HYPOTHESES AND PREDICTION}

Within every population of bird-pollinated plants at Monteverde, floral neighborhoods varied conspicuously in density and species composition. We used this natural variation to examine effects of isolation on pollination. Prior to the investigation, we erected null and alternate hypotheses based on the most straightforward current theories concerning the effects of neighboring flowers on one another's pollination. First, we formulated four alternate hypotheses concerning the effects of neighborhood on number of conspecific pollen grains received by the end of a flower's life:

$H_{A} 1$ : With other variables controlled, number of conspecific pollen grains on the stigma increases with increasing number of flowers on the plant.

$H_{A}$ 2: With other variables controlled, number of conspecific pollen grains on the stigma increases with increasing density of conspecific flowers among neighboring plants.
$H_{A} 3$ : With other variables controlled, number of conspecific pollen grains on the stigma decreases with increasing density of heterospecific flowers among neighboring plants.

$H_{A} 4$ : With other variables controlled, number of conspecific pollen grains on the stigma increases with increasing proportion of conspecific flowers among neighboring plants.

The first hypothesis reflects the expectation that a pollinator transfers increasing numbers of pollen grains among the flowers on a plant as the plant's flower crop increases. The second reflects the expectation that pollination suffers if a flower is isolated from conspecific plants in the absolute sense. The third and fourth reflect the expectation that pollination suffers if a flower is isolated in the relative sense, by an increase in heterospecific neighbors, regardless of $\left(H_{A} 3\right)$, or relative to $\left(H_{A} 4\right)$, the density of conspecific neighbors.

Based on the same expectations, we also formulated five alternate hypotheses concerning the effects of isolation on the number of heterospecific pollen grains received.

$H_{A}$ 5: With other variables controlled, number of heterospecific grains on the stigma decreases with increasing number of flowers on the plant in question.

$H_{A} 6$ : With other variables controlled, number of heterospecific grains on the stigma increases with an in- 


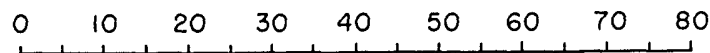

SHORT GUILD:

ERICACEAE

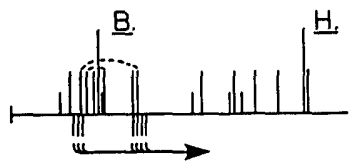

$\ldots$, a DISTYLOUS SPECIES

LONG GUILD:

ERICACEAE

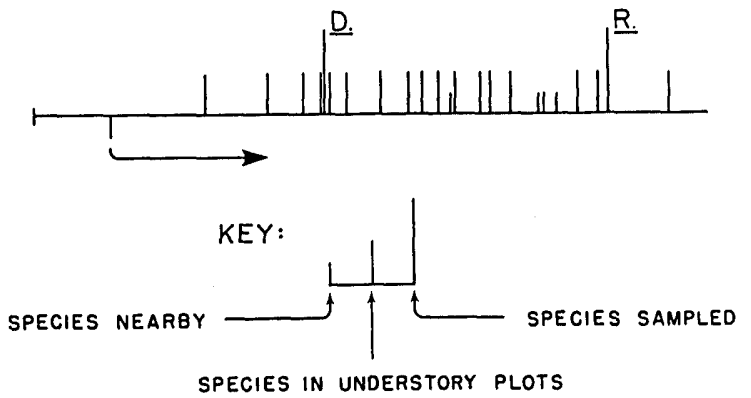

FIG. 2. Interspecific differences among sites of pollen placement in each of the two pollination guilds. In each guild, the horizontal line indicates increasing distance (as indicated by the scale at the top) between nectary, or base of corolla, and midpoint of anthers in the average flower of a given species. Each vertical line thus represents a different species. The tallest vertical lines above the horizontal line represent the four species investigated in this study $(B .=B e s l e r i a, H$. $=H a n s t e i n i a$, $D$. = Drymonia, $R .=$ Razisea). Vertical lines of medium height are other species also occurring on our census plots (samples for this study were not restricted to those plots). Short vertical lines indicate plant species not flowering on the census plots but found nearby (and sometimes found in samples for this investigation). Dashed lines for the short-flowered guild connect anther lengths of pin and thrum flowers in distylous species. Beneath each horizontal line short vertical lines indicate anther distances for species of Ericaceae flowering in canopy and subcanopy: the arrow curving to the right from each line for these species indicates that these flowers tend to dump pollen broadly over the visiting hummingbird's bill and head feathers.

crease in the absolute density of heterospecific flowers among neighboring plants.

$H_{A} 7$ : With other variables controlled, number of heterospecific grains on the stigma decreases with an increase in the absolute density of conspecific flowers among neighboring plants.

$H_{A} 8$ : With other variables controlled, number of heterospecific grains on the stigma increases with an increase in the relative density of heterospecific flowers among neighboring plants.

$H_{A} 9$ : With other variables controlled, number of heterospecific grains on the stigma increases with an increase in the species richness of heterospecific flowers among neighboring plants. (Here we assume that increased species richness increases the chance that some heterospecific pollen on hummingbirds is located where it will be contacted by the stigmas in question.)

Frequent rejection of null hypotheses would indicate that floral neighborhoods affect pollen loads. Conversely, infrequent rejection would indicate that pollen loads are independent of floral neighborhood or are affected in the opposite direction to that expected. Based on floral morphologies and on the observed patterns of hummingbird visits to Monteverde flowers, we pre- dicted that null hypotheses would be rejected for shortflowered plant species but not for long-flowered plant species.

First, at Monteverde, as at many other neotropical sites (Linhart 1973, Stiles 1975, 1981, Feinsinger 1976, 1983, Feinsinger and Colwell 1978), long- and shortbilled hummingbirds forage in different fashions. Shortbilled hummingbirds concentrate on clumps of flowers, often bypassing those isolated in the absolute sense. They usually fly short distances between successive food sources, traversing long distances only rarely. In contrast, long-billed hummingbirds often fly long distances (up to several hundreds of metres, judging from flight vocalizations) between food sources, which often consist of only one or a few isolated flowers of preferred food plants. On the basis of these contrasts, we predicted that absolute isolation is more likely to affect pollination in the short-flowered guild than in the longflowered guild.

Second, the two pollination guilds differ in the extent of morphological divergence among species (Fig. 2). Individual hummingbirds often carry pollen grains of many plant species-in our sample, as many as 15 species (on Lampornis) or 16 species (on Phaethornis) 
TABLE 1. Characteristics of the four plant species investigated. Mean values are given.

\begin{tabular}{|c|c|c|c|c|}
\hline & \multicolumn{2}{|c|}{ Acanthaceae } & \multicolumn{2}{|c|}{ Gesneriaceae } \\
\hline & $\begin{array}{c}\text { Hansteinia } \\
\text { blepharorachis }\end{array}$ & $\begin{array}{l}\text { Razisea } \\
\text { spicata }\end{array}$ & $\begin{array}{l}\text { Besleria } \\
\text { triflora }\end{array}$ & $\begin{array}{l}\text { Drymonia } \\
\text { rubra }\end{array}$ \\
\hline $\begin{array}{l}\text { Corolla length }(\mathrm{mm}) \\
\text { Distance from anthers } \\
\text { to nectary }(\mathrm{mm})\end{array}$ & $\begin{array}{l}22 \\
35\end{array}$ & $\begin{array}{l}46 \\
58\end{array}$ & $\begin{array}{l}15 \\
11\end{array}$ & $\begin{array}{l}42 \\
34\end{array}$ \\
\hline Flower life (d) & $2-3$ & $2-3$ & $3-5$ & $2-4$ \\
\hline Dichogamic? & $\begin{array}{l}\text { Variable; sometimes } \\
\text { protogynous }\end{array}$ & $\begin{array}{l}\text { Variable; sometimes } \\
\text { protogynous }\end{array}$ & Protandrous & Protandrous \\
\hline Mean no. of ovules & $\begin{array}{c}4 \\
\text { Self-comnatible }\end{array}$ & $\begin{array}{c}4 \\
\text { Self }\end{array}$ & $2975 \pm 693(n=3)$ & $1678 \pm 269(n=4)$ \\
\hline $\begin{array}{l}\text { Breeding system } \\
\text { Most frequent } \\
\text { hummingbird visitor }\end{array}$ & $\begin{array}{l}\text { Self-compatible } \\
\text { Lampornis calolaema }\end{array}$ & $\begin{array}{l}\text { Self-compatible } \\
\text { Phaethornis guy }\end{array}$ & $\begin{array}{l}\text { Self-compatible } \\
\text { Lampornis calolaema }\end{array}$ & $\begin{array}{l}\text { Self-compatible } \\
\text { Phaethornis guy }\end{array}$ \\
\hline $\begin{array}{l}\text { Nectar secretion } \\
\left(\mu \mathrm{L} \cdot \text { flower }^{-1} \cdot \mathrm{d}^{-1}\right)\end{array}$ & 3.8 & 9.3 & 10.8 & 30.5 \\
\hline $\begin{array}{l}\text { Sugar concentration in } \\
\text { nectar (\% wet mass) }\end{array}$ & 15.3 & 16.7 & 15.0 & 30.0 \\
\hline
\end{tabular}

(K. G. Murray, personal observation). Many shortflowered species have similarly placed reproductive parts, indicating that pollen from different species is deposited at similar places on hummingbirds. Greater morphological differentiation among coexisting longflowered species (Fig. 2) indicates that pollen of different species is deposited in different places. This contrast between short and long flowers in the extent of interspecific variation may be widespread (see Stiles 1975, 1981, Feinsinger 1983; P. Feinsinger, personal observation). The potential for mixed pollen loads on stigmas, and for pollen loss to inappropriate stigmas (e.g., see Campbell and Motten 1985), may thus be greater for short-flowered plants than for those with long flowers. Therefore, we predicted that relative isolation is more likely to affect pollination in short-flowered plants than in long-flowered plants.

\section{METHODS \\ Data collection}

We examined two pairs of common plant species in the Monteverde Cloud Forest Reserve (Table 1). The two pairs differ greatly from one another, whereas the two species in each pair resemble each other closely in all reproductive characteristics but one: length of flower, and consequently pollination guild (Fig. 1, Table 1). Two Acanthaceae, Hansteinia blepharorachis (shortflowered) and Razisea spicata (long-flowered), are shrubs common in understory and light gaps (Table 1). Some flowers are operationally protogynous. Although stigma and anthers also are usually spatially separated, in a few flowers they are sufficiently close together for self-pollination to occur if stigmas are still receptive. Neither species is apomictic ( $\mathbf{P}$. Feinsinger, personal observation). The occurrence of hybrid swarms at Monteverde suggests that these two species are cross compatible, but we noted almost no overlap in pollinators:
Lampornis calolaema made $84.9 \%$ of the observed visits to Hansteinia (12.4\% came from the short-billed Eupherusa eximia), whereas the long-billed Phaethornis guy made $88.9 \%$ of the legitimate visits to Razisea.

In Besleria triflora and Drymonia rubra (Gesneriaceae), anthers and stigmas are included rather than exserted (Fig. 1). Both have protandrous flowers with many ovules (Table 1). Besleria is a common shrub with short flowers, whereas the long-flowered Drymonia is a climber that usually flowers $2-4 \mathrm{~m}$ above the ground. Lampornis calolaema made $97.4 \%$ of the hummingbird visits we observed to Besleria. Phaethornis guy made $82.6 \%$ of the legitimate visits to Drymonia rubra, and $11 \%$ came from two other long-billed hummingbirds (Heliodoxa jacula and Campylopterus hemileucurus).

Except for unusually large Besleria shrubs or clumps of Hansteinia, no plant of these four species was defended as a feeding territory. Therefore, our results are not complicated by the effects of territoriality on pollen flow (cf. Linhart 1973, Feinsinger 1978).

These four species were not randomly chosen from the available bird-pollinated plants. We chose species that occurred frequently, whose flowers were accessible and unlikely to self-pollinate without the intervention of a hummingbird. Some features of Razisea in particular were atypical for long flowers, such as its tiny stigmatic surface, low nectar volume and sugar concentration, and low frequency of pollinator visits. In other respects, though, all four species typified their guilds. Most other hummingbird-pollinated species at Monteverde are also self-compatible (J. H. Beach, W. H. Busby, and W. Z. Pounds, personal communication) and have flowers that last $>1$ d. As Fig. 2 suggests, some species have exserted reproductive parts like the Acanthaceae we sampled, whereas many have included reproductive parts like the two Gesneriaceae.

For each species, during three periods of its 1982- 
TABLE 2. Variables examined among the flowers sampled.

A) Dependent variables

1) CONGR: Number of conspecific pollen grains on stigma (log-transformed)

2) HEGR: Number of heterospecific pollen grains on stigma (log-transformed)

3) H: Number of species of heterospecific grains

4) TUBES: Number of pollen tubes in style (Gesneriaceae) (log-transformed)

B) Independent variables

1) CEN: Number of flowers on central plant

2) DCONS: Number of conspecific flowers $/ 314.16 \mathrm{~m}^{2}$ (exclusive of CEN)

3) DHETS: Number of heterospecific flowers $/ 314.16 \mathrm{~m}^{2}$

4) DCONS + DHETS: Total number of flowers in relevant guild $/ 314.16 \mathrm{~m}^{2}$

5) PRCFL: [DCONS/(DCONS + DHETS)], or proportion of conspecifics among neighboring flowers (arcsine-transformed)

6) D: Number of species of heterospecific flowers in neighborhood

1983 flowering season we examined stigmas and styles from flowers on 28-40 different focal plants. In each of these 12 sampling runs, we counted the open, undamaged flowers on each focal plant, and collected those in late female phase for later examination of pollen loads and pollen tubes. We collected only female flowers that were obviously herkogamic (i.e., those without the potential for self-pollination). Next, we quantified the focal plant's floral neighborhood, defined as all other plants in the same pollination guild within a vertical cylinder of $10 \mathrm{~m}$ radius (basal area of $314 \mathrm{~m}^{2}$ ) or the 10 nearest neighboring guildmate plants if there were not 10 within the specified cylinder. We counted flowers on each guildmate plant and measured its distance from the focal plant. We also counted neighboring flowers on plants in the other pollination guild and flowers on insect-pollinated plants known to attract hummingbirds. Two people could process $1-10$ (usually 3-4) focal plants per day. Rain washed pollen from the exposed stigmas of the two Acanthaceae; therefore, we sampled those species only on rainless days.

For the two Acanthaceae, in the field we snipped off the stigma and $\approx 1 \mathrm{~cm}$ of style, mounting this on a microscope slide under cellophane tape or a cover slip. We preserved the remainder of each style in formalinacetic acid (FAA). For the two Gesneriaceae, we brought whole flowers to the laboratory, where we mounted stigmas on microscope slides and preserved the styles. Using microscopes with either Hoffman optics or epifluorescence illumination, we counted (or estimated, for large pollen loads) and identified as far as possible all pollen grains on each stigma. By using Hoffman optics, we underestimated the numbers of heterospecific grains during the first Drymonia sample, but presumably other errors (such as variation among different observers' estimates of the largest gesneriad pollen loads) were random.

Because all four species are self-compatible, we assumed that the number of conspecific pollen grains was an index to the number of male gametophytes. To verify this assumption, we counted pollen tubes (Martin 1959) in the preserved styles of the two Gesneriaceae. Despite attempts with several techniques, we were unable to discern pollen tubes in either Acanthaceae.

\section{Statistical analysis}

In each sampling run, we tabulated three (Acanthaceae) or four (Gesneriaceae) dependent variables (Table $2 \mathrm{~A}$ ) and calculated five independent variables defining the neighborhood surrounding the flower (Table 2B). We constructed two alternate statistical models relating each dependent variable to independent variables, each model a complete descriptor of the neighborhood surrounding a plant but without the bias of strong collinearity among the independent variables. The "absolute density" model emphasized the absolute numbers of conspecific and heterospecific flowers, whereas the "relative density" model emphasized the ratio of conspecific to heterospecific flowers (Table 3). We separated effects of conspecific flowers occurring on neighboring plants (DCONS) from flowers on the focal plant itself (CEN), because the former may affect whether or not a bird decides to forage in the neighborhood, and the pollen load it is carrying upon arrival at the focal plant, whereas the latter may affect whether or not the bird decides to forage at that plant, and how much self pollen is moved among flowers.

TABLE 3. Models used in the multiple regression analyses. Independent variables (defined in Table 2) were forced into the stepwise regression in the order indicated. Superscript signs occur where theory gives a basis for a directional prediction of the relationship between dependent and independent variables.

\begin{tabular}{|c|c|c|}
\hline $\begin{array}{c}\text { Dependent } \\
\text { variable }\end{array}$ & Absolute density model* & Relative density model* \\
\hline $\begin{array}{l}\text { CONGR } \\
\text { HEGR } \\
\text { H }\end{array}$ & $\begin{aligned} \text { CONGR } & =\mathrm{F}\left(\mathrm{CEN}^{+}, \mathrm{DCONS}^{+}, \text {DHETS }^{-}\right) \\
\text {HEGR } & =\mathrm{F}\left(\mathrm{DHETS}^{+}, \mathrm{CEN}^{-}, \mathrm{DCONS}^{-}, \mathrm{D}^{+}\right) \\
\mathrm{H} & =\mathrm{F}\left(\mathrm{D}^{+}, \mathrm{CEN}^{-}, \text {DHETS }^{+}, \text {DCONS }^{-}\right)\end{aligned}$ & $\begin{aligned} \text { CONGR } & =\mathrm{F}\left(\mathrm{CEN}^{+}, \mathrm{PRCFL}^{+},\left[\mathrm{DCONS}+\mathrm{DHETS}^{+}\right)\right. \\
\mathrm{HEGR} & =\mathrm{F}\left(\mathrm{PRCFL}^{-}, \mathrm{CEN}^{-},[\mathrm{DCONS}+\mathrm{DHETS}) \S, \mathrm{D}^{+}\right. \\
\mathrm{H} & =\mathrm{F}\left(\mathrm{D}^{+}, \mathrm{CEN}^{-}, \mathrm{PRCFL}^{-},[\mathrm{DCONS}+\mathrm{DHET}]\right) \S\end{aligned}$ \\
\hline
\end{tabular}



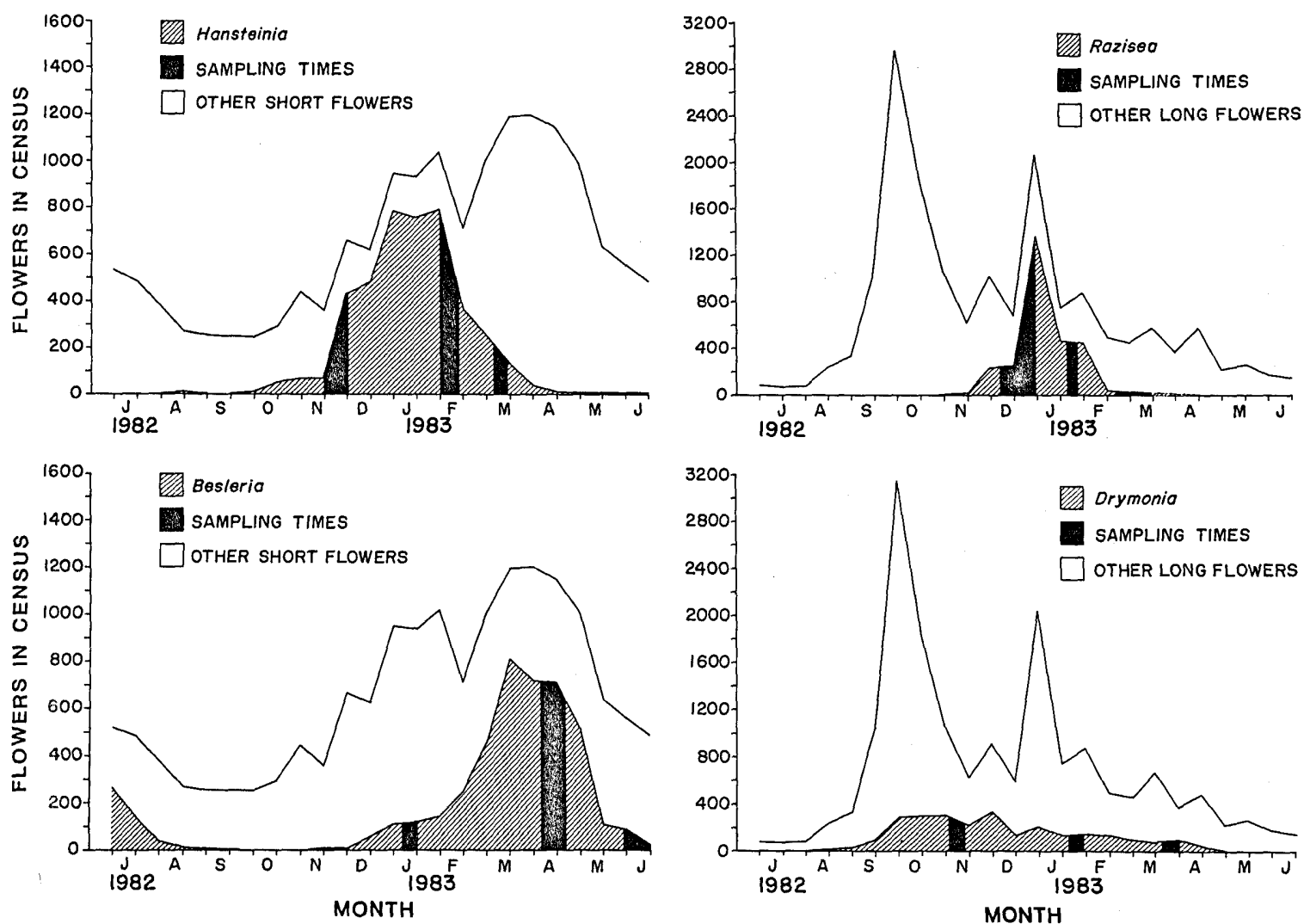

Fig. 3. Phenologies of total flowering in each guild of hummingbird-pollinated plants, and of each species investigated in this study. $Y$ axis indicates numbers of flowers counted on census plots in forest understory and treefall gaps. For Razisea and Drymonia, the upper line indicates total number of fowers in the long-flowered guild (including those species); for Besleria and Hansteinia, total number of flowers in the short-flowered guild. The flowering phenology of each of the four species, as quantified on census plots, is shown by the hatched area. For each species, the three solid vertical bars show the duration and timing of each of the three sampling runs performed in this study.

After data transformations where appropriate (Table 2), we subjected the data set from each sampling run to stepwise multiple regression, using the mean pollen load of the $\geq 1$ flowers sampled per focal plant as the dependent variable, and forcing the independent variables in the expected order of decreasing importance as indicated in Table 3. After inspecting for high collinearity, at each step we determined whether or not adding that variable significantly decreased the residual variance. For the $i^{\text {th }}$ variable examined, we calculated the $F$ ratio between the residual ss (sum of squares) at step $i-1$ and the residual ss at step $i$, and determined the significance of that ratio with Table $S$ in Rohlf and Sokal (1969) with $\mathrm{df}=1,(n-i-1)$. This technique is superior to Principal Components Analysis or a standard multiple regression for examining the models, because it distinguishes without bias the effects of different variables, as long as collinearity among variables is not high and their order is determined a priori (Connor and Simberloff 1978; J. G. Saw, personal communication). With this procedure, however, the $R^{2}$ val- ue for the whole model cannot objectively be tested for significance.

For each analysis, we weighted each observation (mean pollen load) by the number of flowers sampled on that plant. Such a weighted regression analysis (cf. Steel and Torrie 1960:181) is statistically unbiased, but it loses information on variation among pollen loads received by individual flowers within plants. Therefore, to ensure that within-plant variation, independent of floral neighborhood, did not substantially alter regressions, we re-ran all analyses, treating each individual flower as an observation. These alternate analyses were not examined for statistical significance, however, because degrees of freedom were artificially inflated.

In each of the 36 analyses ( 12 data sets $\times 3$ dependent variables), we calculated independent variables in three different ways. First, we defined independent variables (Table 3) simply as the raw numbers of flowers of the species sampled and its guildmates. Second, we weighted the numbers of flowers counted in differ- 
TABLE 4. Ranges of independent variables in each sampling run. Codes are defined in Table 2.

\begin{tabular}{ccccccccc}
\hline \hline & & \multicolumn{7}{c}{ Independent variable } \\
\cline { 6 - 9 } Species & $\begin{array}{c}\text { No. } \\
\text { plants }\end{array}$ & $\begin{array}{c}\text { Total no. } \\
\text { flowers }\end{array}$ & CEN & DCONS & DHETS & $\begin{array}{c}\text { DCONS }+ \\
\text { DHETS }\end{array}$ & PRCFL & D \\
\hline Hansteinia & & & & & & & & \\
Run 1 & 35 & 191 & $2-56$ & $0-78$ & $0.1-162$ & $1-240$ & $0-0.98$ & $1-5$ \\
Run 2 & 31 & 128 & $3-22$ & $3-137$ & $0-77$ & $4-148$ & $0.10-1.0$ & $0-4$ \\
Run 3 & 34 & 102 & $1-15$ & $0-107$ & $1-71$ & $1-116$ & $0-0.96$ & $1-5$ \\
Razisea & & & & & & & & \\
Run 1 & 30 & 199 & $3-44$ & $2-533$ & $0-49$ & $3-534$ & $0.15-1.0$ & $0-4$ \\
Run 2 & 40 & 223 & $2-22$ & $6-160$ & $0-30$ & $8-160$ & $0.24-1.0$ & $0-4$ \\
Run 3 & 33 & 94 & $1-12$ & $0-60$ & $0-62$ & $0-64$ & $0-1.0$ & $0-6$ \\
Besleria & & & & & & & & \\
Run 1 & 34 & 126 & $1-43$ & $0-37$ & $1-131$ & $1-132$ & $0-0.95$ & $1-6$ \\
Run 2 & 36 & 143 & $3-132$ & $0-296$ & $0-63$ & $2-296$ & $0-1.0$ & $0-4$ \\
Run 3 & 32 & 62 & $1-12$ & $0-26$ & $0-103$ & $1-110$ & $0-1.0$ & $0-4$ \\
Drymonia & & & & & & & & \\
Run 1 & 32 & 118 & $2-23$ & $0-55$ & $1-266$ & $4-321$ & $0-0.90$ & $2-5$ \\
Run 2 & 32 & 57 & $1-13$ & $0-28$ & $1-185$ & $1-185$ & $0-0.96$ & $1-5$ \\
Run 3 & 36 & 54 & $1-8$ & $0-17$ & $1-71$ & $2-79$ & $0-0.91$ & $1-6$ \\
\hline
\end{tabular}

ent species, regardless of guild, by their relative popularity as determined from observation data gathered during 1981-1982. For any neighboring species, whether adapted for long-billed hummingbirds, shortbilled hummingbirds, or insects, popularity was defined as the frequency of visits its flowers received from the hummingbird pollinators (short-billed or longbilled) of the species being sampled. Third, because in some species sampled (especially Razisea) flowers from different plants were quite intermingled, we treated all conspecific flowers within $2 \mathrm{~m}$ of the actual central plant as CEN (see Table 2) and changed the values of the remaining independent variates accordingly.

\section{RESULTS \\ Neighborhoods}

The overall abundance of flowers in each pollination guild changed markedly between sampling periods for each of the four species examined (Fig. 3). These periods included times of relatively low overall density and times of high density for each species. In each of the 12 runs we sampled flowers from a wide variety of neighborhoods, ranging from sites with few bird-visited flowers whatsoever to dense stands of conspecific flowers or clusters of heterospecific flowers containing as many as six species (Table 4).

\section{Pollen loads}

Loads of conspecific grains varied widely among flowers within each sampling run (Table 5). Considerable variation occurred within plants. For example, in each of the six sampling runs on Besleria and Drymonia, the plant having the flower with the greatest recorded number of conspecific grains also had at least one flower, of the same age, with zero or few grains.
Many pollen loads were small. For example, while most Besleria and Drymonia flowers received some pollen, relatively few (4-16\% in Drymonia, $13-68 \%$ in Besleria) received an "adequate" load, defined conservatively as a grain for every ovule (Table 5). Many $R a$ zisea flowers received no pollen whatsoever, and few received as many as four grains. Only in Hansteinia did the majority of flowers receive at least as many grains as the number of ovules (Table 5).

The frequency of adequate loads differed significantly over the flowering season for each species (Table 5). In both short-flowered species, frequency of adequate loads was higher at midseason than either early or late in the flowering season, despite the similar range of neighborhoods in the three sampling runs (Table 4). For both long-flowered species, the frequency of adequate loads in the second sampling run exceeded that in the late-season run (Table 5) but not in the earliest run.

We could not assess pollen tube growth in Acanthaceae, but assume that numbers of pollen tubes in styles of these two self-compatible species are correlated with the numbers of conspecific grains received on the stigmas. In both species of Gesneriaceae, counts of pollen tubes were highly correlated with independent counts of conspecific grains (Table 6).

Some flowers received heterospecific as well as conspecific grains (Table 5). The frequency of stigmas receiving foreign grains tended to be lower in the Acanthaceae, whose small stigmas and exserted anthers contacted visiting hummingbirds in quite unique spots (cf. Fig. 2), than in the Gesneriaceae, whose large stigmatic surfaces were potentially exposed to pollen of several species (Fig. 2). There were few seasonal effects on the frequency of stigmas receiving heterospecific grains (Table 5). 
TABLE 5. Summary of pollen loads on stigmas sampled. Sample sizes as in Table 4. Numbers of ovules reported in Table 1. values for HEGR and $\mathrm{H}$ in Drymonia run 1 [numbers in square brackets] are underestimates, and counts of CONGR for all Besleria and Drymonia runs are subject to estimator error.

\begin{tabular}{|c|c|c|c|c|c|c|c|c|c|}
\hline & \multicolumn{4}{|c|}{ Conspecific grains (CONGR) } & \multicolumn{3}{|c|}{ Heterospecific grains (HEGR) } & \multirow{2}{*}{\multicolumn{2}{|c|}{$\begin{array}{c}\text { No. heterospecific } \\
\text { species }(\mathrm{H})\end{array}$}} \\
\hline & \multicolumn{2}{|c|}{ Number of grains } & \multirow{2}{*}{$\begin{array}{l}\% \text { with } \\
>0+\end{array}$} & \multirow{2}{*}{$\begin{array}{l}\% \text { with } \geq \\
\text { no. ovules } \ddagger\end{array}$} & \multicolumn{2}{|c|}{ Number of grains } & \multirow{2}{*}{$\begin{array}{c}\% \text { with } \\
>0+\end{array}$} & & \\
\hline & Range & $\bar{X} \pm s$ & & & Range & $\bar{X} \pm s$ & & Range & $\bar{X} \pm s$ \\
\hline \multicolumn{10}{|c|}{ Hansteina } \\
\hline $\begin{array}{l}\text { Run } 1 \\
\text { Run } 2 \\
\text { Run } 3\end{array}$ & $\begin{array}{l}0-75 \\
0-58 \\
0-140\end{array}$ & $\begin{array}{l}10.5 \pm 12.1 \\
14.7 \pm 14.0 \\
11.1 \pm 18.6\end{array}$ & $\begin{array}{l}79 \\
85 \\
66\end{array}$ & $\begin{array}{l}63^{*} \\
74^{*} \\
50^{*}\end{array}$ & $\begin{array}{l}0-7 \\
0-65 \\
0-39\end{array}$ & $\begin{array}{l}0.2 \pm 0.8 \\
2.5 \pm 7.7 \\
1.2 \pm 4.5\end{array}$ & $\begin{array}{l}10 \\
33 \\
22\end{array}$ & $\begin{array}{l}0-3 \\
0-3 \\
0-3\end{array}$ & $\begin{array}{l}0.1 \pm 0.4 \\
0.4 \pm 0.7 \\
0.3 \pm 0.7\end{array}$ \\
\hline \multicolumn{10}{|l|}{ Razisea } \\
\hline $\begin{array}{l}\text { Run } 1 \\
\text { Run } 2 \\
\text { Run } 3\end{array}$ & $\begin{array}{l}0-60 \\
0-83 \\
0-39\end{array}$ & $\begin{array}{l}4.7 \pm 9.8 \\
5.9 \pm 12.6 \\
2.5 \pm 6.5\end{array}$ & $\begin{array}{l}41 \\
48 \\
35\end{array}$ & $\begin{array}{l}26 \\
30_{* *} \\
15^{* *}\end{array}$ & $\begin{array}{l}0-85 \\
0-32 \\
0-104\end{array}$ & $\begin{array}{l}1.6 \pm 8.2 \\
0.9 \pm 3.6 \\
3.6 \pm 15.1\end{array}$ & $\begin{array}{l}14 \\
16 \\
17\end{array}$ & $\begin{array}{l}0-4 \\
0-4 \\
0-3\end{array}$ & $\begin{array}{l}0.2 \pm 0.6 \\
0.2 \pm 0.5 \\
0.3 \pm 0.6\end{array}$ \\
\hline \multicolumn{10}{|l|}{ Besleria } \\
\hline $\begin{array}{l}\text { Run } 1 \\
\text { Run } 2 \\
\text { Run } 3\end{array}$ & $\begin{array}{l}0-38400 \\
0-78000 \\
0-26900\end{array}$ & $\begin{array}{l}1916 \pm 4550 \\
3375 \pm 7807 \\
1990 \pm 4652\end{array}$ & $\begin{array}{l}90 \\
97 \\
98\end{array}$ & $\begin{array}{l}17^{* * * *} \\
68^{* * *}\end{array}$ & $\begin{array}{l}0-1283 \\
0-397 \\
0-482\end{array}$ & $\begin{array}{l}91 \pm 203 \\
33 \pm 62 \\
98 \pm 121\end{array}$ & $\begin{array}{l}71 \\
71^{* * *} \\
95^{*}\end{array}$ & $\begin{array}{l}0-5 \\
0-5 \\
0-6\end{array}$ & $\begin{array}{l}1.5 \pm 1.3 \\
1.5 \pm 1.2 \\
2.7 \pm 1.6\end{array}$ \\
\hline \multicolumn{10}{|c|}{ Drymonia } \\
\hline $\begin{array}{l}\text { Run } 1 \\
\text { Run } 2 \\
\text { Run } 3\end{array}$ & $\begin{array}{l}0-7000 \\
0-22500 \\
0-3500\end{array}$ & $\begin{array}{r}624 \pm 1111 \\
1366 \pm 3361 \\
453 \pm 679\end{array}$ & $\begin{array}{l}95 \\
98 \\
98\end{array}$ & $\begin{array}{c}11 \\
16 \\
4\end{array}$ & $\begin{array}{c}{[0-472]} \\
0-1256 \\
0-510\end{array}$ & $\begin{array}{c}{[6.6 \pm 46.4]} \\
40 \pm 181 \\
28 \pm 92\end{array}$ & $\begin{array}{c}{[14]} \\
53 \\
44\end{array}$ & $\begin{array}{c}{[0-2]} \\
0-4 \\
0-3\end{array}$ & $\begin{array}{c}{[0.2 \pm 0.5]} \\
0.9 \pm 1.1 \\
0.6 \pm 0.8\end{array}$ \\
\hline
\end{tabular}

$\dagger$ Percent of flowers with $>0$ grains.

$\ddagger$ Percent of flowers with no. grains $\geq$ no. ovules.

${ }^{*} P<.05, * * P<.01, * * * P<.001$; significant differences (chi-square test) between runs in the frequency of flowers receiving at least as many grains as they have ovules (Column 5) or of flowers receiving heterospecific grains (Column 8).

\section{Effects of neighborhood on conspecific pollen loads}

The independent variables we examined sometimes, but by no means always, affected significantly the number of conspecific grains that flowers received (Table 7). First, null hypotheses of the "absolute density" model (see Table 3 ) were rarely rejected for either short or long flowers. Number of flowers on the focal plant (CEN) affected number of conspecific grains received (CONGR) in 2 of 12 sampling runs (both Razisea). In 2 of 12 runs (one each for short-flowered species), CONGR increased with an increase in the number of conspecific flowers in the neighborhood (DCONS). In none of the 12 sampling runs did increased density of heterospecific flowers in the neighborhood (DHETS) lead to a significant decrease in the conspecific pollen loads received by flowers. In fact, counter to conventional expectations (as represented in Table 3), in one case (Drymonia Run 1) CONGR was positively related to DHETS (Table 7).

In the "relative density" model (Table 3), the null hypothesis of greatest interest was rejected more often for short flowers than for long flowers (Table 7), as we had predicted. Number of conspecific grains (CONGR) increased significantly with increases in the proportion of conspecifics among neighboring flowers (PRCFL) in three of six runs on short-flowered plants (one for $\mathrm{Han}$ steinia, two for Besleria). In contrast, CONGR on long flowers never increased with increasing PRCFL, and in two cases (one for each long-flowered species) there was actually a strong negative relationship between the two variables. In only one run (Drymonia) was there a significant effect of the total number of guildmate flowers (DCONS + DHETS).

To determine if incorporating within-plant variation into the analysis weakened even further the effects of neighborhood, we re-ran each regression using the pollen load of each flower, rather than the mean load per plant, as the dependent variable. In nearly every case this alternate approach increased, rather than decreased, the number of apparently strong relationships between CONGR and independent variables. Both $F$ values and tests of significance in the per-flower analyses are biased by inflated degress of freedom, however.

TABLE 6. Pearson product-moment correlations between logarithms of the two independent measures of potential fecundity in the two species of Gesneriaceae, both selfcompatible: number of conspecific pollen grains counted on the stigma (CONGR) and number of pollen tubes growing down the style (TUBES).*

\begin{tabular}{lccc}
\hline & & \multicolumn{2}{c}{ Correlation coefficient } \\
\cline { 3 - 4 } Species & Sampling run & $r$ & No. flowers \\
\hline Besleria & Run 1 & 0.7964 & 126 \\
& Run 2 & 0.6847 & 128 \\
& Run 3 & 0.6061 & 52 \\
Drymonia & Run 1 & 0.7195 & 118 \\
& Run 2 & 0.7128 & 51 \\
& Run 3 & 0.6932 & 52 \\
\hline
\end{tabular}

* Both counts are subject to observer error (see Methods: Data Collection). 
TABLE 7. Results of weighted stepwise multiple regression applied to mean value of CONGR (number of conspecific grains on stigma) per focal plant. Independent variables forced into regression in order described in Table 3 . Weighting factor ( $w$ $\geq 1$ ) was number of flowers sampled on that plant. $\dagger$

\begin{tabular}{|c|c|c|c|c|c|c|c|c|}
\hline & \multirow{2}{*}{\multicolumn{4}{|c|}{ Absolute density model }} & \multicolumn{4}{|c|}{ Relative density model } \\
\hline & & & & & & & DCONS + & \\
\hline & CEN & DCONS & DHETS & $R^{2}$ & CEN & PRCFL & DHETS & $R^{2}$ \\
\hline & \multicolumn{3}{|c|}{$F$ values } & \multicolumn{5}{|c|}{$F$ values } \\
\hline Hansteinia & & & & & & & & \\
\hline $\begin{array}{l}\text { Run } 1 \\
\text { Run } 2 \\
\text { Run 3 }\end{array}$ & $\begin{array}{l}+3.99_{(1,33)} \\
-0.22_{(1,29)} \\
+1.38_{(1,32)}\end{array}$ & $\begin{array}{c}+0.82 \\
+6.64^{*} \\
0.00\end{array}$ & $\begin{array}{r}0.00 \\
-0.01 \\
+0.22\end{array}$ & $\begin{array}{l}0.130 \\
0.198 \\
0.048\end{array}$ & $\begin{array}{l}+3.98_{(1,33)} \\
-0.22_{(1,29)} \\
+1.38_{(1,32)}\end{array}$ & $\begin{array}{l}+1.32 \\
+5.36^{*} \\
+0.22\end{array}$ & $\begin{array}{l}+0.67 \\
+3.07 \\
+0.12\end{array}$ & $\begin{array}{l}0.161 \\
0.252 \\
0.052\end{array}$ \\
\hline \multicolumn{9}{|l|}{ Besleria } \\
\hline $\begin{array}{l}\text { Run } 1 \\
\text { Run } 2 \\
\text { Run } 3\end{array}$ & $\begin{array}{l}+1.91_{(1,32)} \\
+0.63_{(1,34)} \\
+1.38_{(1,30)}\end{array}$ & $\begin{array}{c}+12.07 * * \\
-0.07 \\
+3.10\end{array}$ & $\begin{array}{l}+0.29 \\
-0.26 \\
-2.05\end{array}$ & $\begin{array}{l}0.328 \\
0.028 \\
0.196\end{array}$ & $\begin{array}{l}+1.91_{(1,32)} \\
+0.63_{(1,34)} \\
+1.38_{(1,30)}\end{array}$ & $\begin{array}{l}+4.69^{*} \\
-0.04 \\
+8.65^{* *}\end{array}$ & $\begin{array}{l}+1.96 \\
-0.10 \\
+0.03\end{array}$ & $\begin{array}{l}0.231 \\
0.023 \\
0.264\end{array}$ \\
\hline \multicolumn{9}{|l|}{ Razisea } \\
\hline $\begin{array}{l}\text { Run } 1 \\
\text { Run } 2 \\
\text { Run } 3\end{array}$ & $\begin{array}{l}+5.06_{(1,28)}^{*} \\
+0.02_{(1,38)} \\
+7.00_{(1,31)}^{*}\end{array}$ & $\begin{array}{r}0.00 \\
+2.64 \\
+3.72\end{array}$ & $\begin{array}{l}+0.10 \\
-4.03 \\
+0.22\end{array}$ & $\begin{array}{l}0.252 \\
0.161 \\
0.275\end{array}$ & $\begin{array}{l}+5.06^{*}{ }_{(1,28)} \\
+0.02_{(1,38)} \\
+7.00_{(1,30)}^{*}\end{array}$ & $\begin{array}{l}-9.64^{\circ} \\
+2.83 \\
+0.02\end{array}$ & $\begin{array}{l}+2.59 \\
+0.52 \\
+0.70\end{array}$ & $\begin{array}{l}0.432 \\
0.085 \\
0.204\end{array}$ \\
\hline \multicolumn{9}{|l|}{ Drymonia } \\
\hline $\begin{array}{l}\text { Run } 1 \\
\text { Run } 2 \\
\text { Run } 3\end{array}$ & $\begin{array}{l}+1.13_{(1,30)} \\
+0.38_{(1,30)} \\
+0.54_{(1,34)}\end{array}$ & $\begin{array}{l}+3.05 \\
+0.40 \\
-5.46^{\circ}\end{array}$ & $\begin{array}{l}-4.12 \\
+8.09^{\circ} \\
+1.02\end{array}$ & $\begin{array}{l}0.240 \\
0.244 \\
0.181\end{array}$ & $\begin{array}{l}+1.13_{(1,30)} \\
+0.38_{(1,30)} \\
+0.54_{(1,34)}\end{array}$ & $\begin{array}{l}+1.47 \\
-2.60 \\
-4.76^{\circ}\end{array}$ & $\begin{array}{l}+0.01 \\
+6.02^{*} \\
-0.13\end{array}$ & $\begin{array}{l}0.083 \\
0.254 \\
0.379\end{array}$ \\
\hline \multicolumn{9}{|c|}{ Summary (No. times $H_{0}$ rejected) } \\
\hline $\begin{array}{l}\text { Short flowers } \\
\text { Long flowers }\end{array}$ & $\begin{array}{l}0 \\
2\end{array}$ & $\begin{array}{l}2 \\
0\end{array}$ & $\begin{array}{l}0 \\
0\end{array}$ & & $\begin{array}{l}0 \\
2\end{array}$ & $\begin{array}{l}3 \\
0\end{array}$ & $\begin{array}{l}0 \\
1\end{array}$ & \\
\hline
\end{tabular}

${ }^{*} P<.05,{ }^{* *} P<.01,{ }^{* * *} P<.001 ;$ strength of effect in the direction expected (Table 3 ).

${ }^{0}$ Indicates strong effect in the direction opposite to that stated in $H_{A}$, so $H_{0}$ not rejected.

$\dagger$ Models described in Table 3 and in Methods: Statistical Analysis; see Table 2 for abbreviations. (Values for CONGR were log-transformed, values for PRCFL arcsine transformed.) The values given are $F$ values (degrees of freedom [1,n-i1] for the $i^{\text {th }}$ variable added, given for $i=1$ [CEN] only) for the effect of adding each successive independent variable on the residual ss.

Because there were no marked qualitative effects on the regressions as reported in Table 7, we do not report the numerical results from the alternate approach.

\section{Effects of neighborhood on heterospecific pollen loads}

The effects of neighborhood on the number of heterospecific pollen grains received (HEGR) followed no clear pattern (Table 8). Relationships between indepdendent variables and HEGR were not consistent within a given guild, a given plant family (Acanthaceae vs. Gesneriaceae), or even within a species. Some effects were counter-intuitive and opposite to conventional models (Table 3 ). Null hypotheses were infrequently rejected, in some cases because there was little statistical effect, in others because a strong statistical effect existed but in the opposite direction of that expected. For example, HEGR increased with increases in the density of conspecific flowers (DCONS) more often than it decreased. Overall, in seven cases (out of 96 possible) there was a statistically significant effect in the direction predicted (Table 3), but in nine other cases there was a strong effect in the opposite direction. Among the 12 sampling runs, there was very little difference in the degree to which the models of Table 3 applied to short-flowered and long-flowered plants, respectively. We found no substantial differences between the results reported in Table 8 and results from the alternate approach that used pollen load on each flower as the dependent variable.

Some counterintuitive relationships between HEGR and neighborhood may result from a positive relationship between HEGR and CONGR. In our data, the sign of all 12 correlation coefficients between CONGR and HEGR was positive, and eight of the 12 coefficients were significant (Table 9). Correlations were especially strong for Razisea.

In all 12 runs the dependent variable $H$, number of species of heterospecific grains, was highly correlated with HEGR, the total number of heterospecific grains received. Correlation coefficients ranged from 0.72 to 0.96 . Thus, the statistical results for $H$ were qualitatively very similar to those for HEGR and are not reported here.

\section{Alternative calculations of independent variables}

Results reported in Tables 7 and 8 are based on the simplest definition of independent variables: counts of flowers on conspecific and heterospecific plants. Nectar 
TABLE 8. Results of weighted stepwise multiple regression applied to mean value of HEGR (number of heterospecific grains on stigma) per focal plant. See Table 7, and Methods: Statistical Analysis, for explanation. Values for HEGR were logtransformed, values for PRCFL arcsine transformed. Note that effect of adding CEN can differ between the two models.

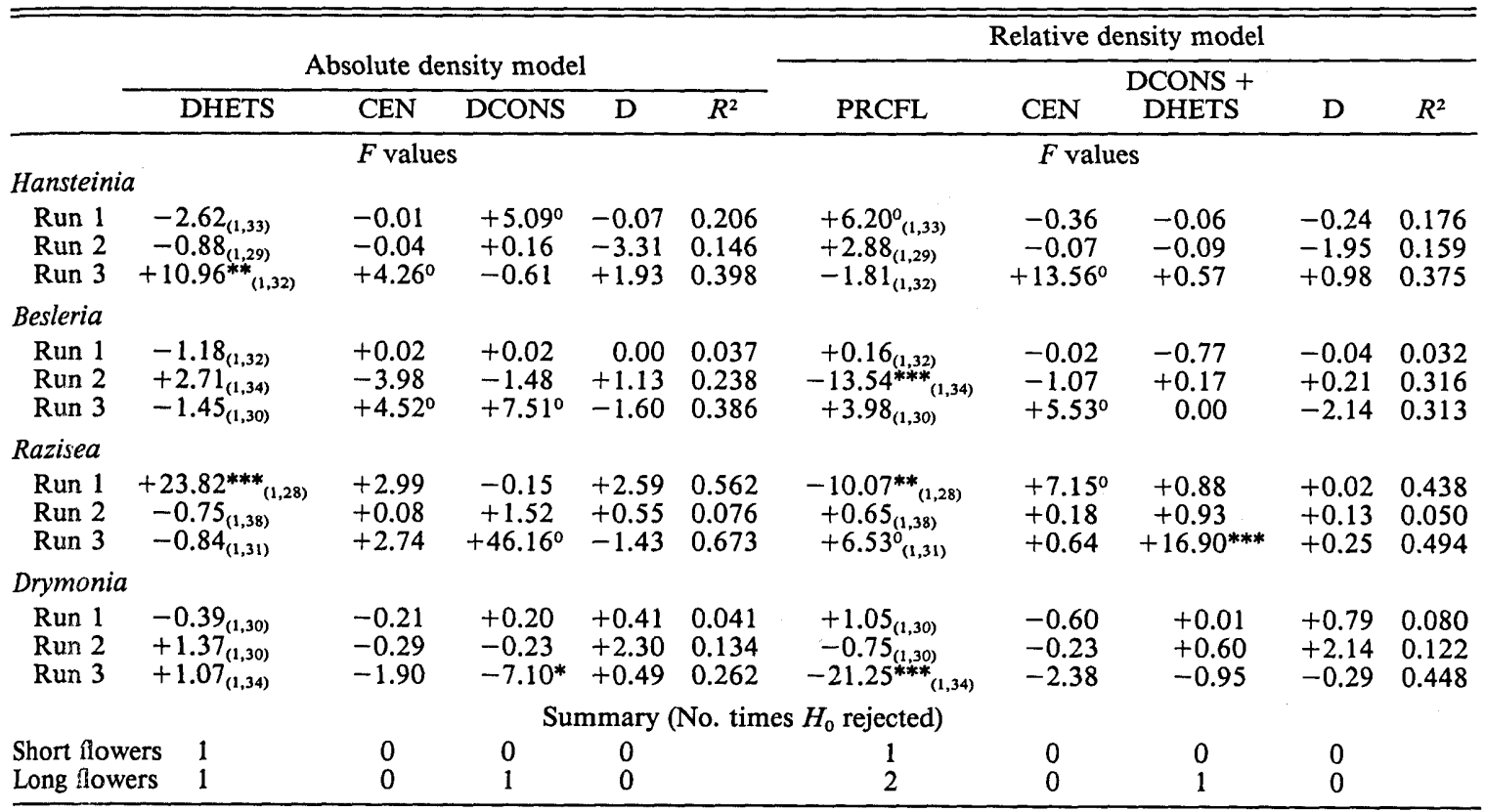

secretion rates, conspicuousness, and popularity with birds varied among species, however. Therefore, we also characterized neighborhoods on the basis of attractiveness to birds, weighting flower numbers by mean frequency of visits by the relevant hummingbird group. We also repeated all regressions calculating CEN not as the actual number of flowers on the central plant,

TABLE 9. Pearson product-moment correlations between CONGR (conspecific pollen loads) and HEGR (heterospecific pollen loads) in each sampling run, with each flower treated as a separate observation.

\begin{tabular}{lll}
\hline \hline Species & $n$ & \multicolumn{1}{c}{$r$} \\
\hline Hansteinia & & \\
Run 1 & 191 & 0.0824 \\
Run 2 & 128 & $0.2331^{*}$ \\
Run 3 & 102 & $0.2691^{* *}$ \\
Razisea & & \\
Run 1 & 199 & $0.4115^{* * *}$ \\
Run 2 & 223 & $0.4690^{* * *}$ \\
Run 3 & 94 & $0.4407^{* * *}$ \\
Besleria & & \\
Run 1 & 126 & $0.5563^{* * *}$ \\
Run 2 & 143 & $0.3450^{* * *}$ \\
Run 3 & 62 & 0.2036 \\
Drymonia & & \\
Run 1 & 118 & 0.1521 \\
Run 2 & 57 & $0.4317^{* * *}$ \\
Run 3 & 54 & 0.2478 \\
\hline
\end{tabular}

${ }^{*} P<.05,{ }^{* *} P<.01,{ }^{* * *} P<.001$. but as all conspecific flowers within a $2 \mathrm{~m}$ radius of that plant.

Neither alternative approach changed the general conclusions suggested by Tables 7 and 8 . Using a standard $2 \mathrm{~m}$ radius to determine CEN changed $F$ values but changed their significance only rarely (Table 10A). Weighting conspecific and heterospecific flowers (regardless of guild) by attractiveness to potential pollinators also changed $F$ values, but a comparison of Table 10B (which summarizes the distribution of significant results) with the summaries in Tables 7 and 8 reveals only one minor change in the overall frequency with which we could reject $H_{\mathrm{o}}$. Therefore, neither of these more complex approaches to indepdendent variables leads to new insight. Although we do not deny that differential attractiveness of plant species to pollinators plays a role in neighborhood effects (cf. Rathcke 1983), in the discussion below we emphasize the results from the analyses that use the simplest approach (Tables 7 and 8).

\section{Discussion}

\section{The complex effects of floral neighborhoods}

Most pollination ecologists expect some relationship to exist between floral neighborhood and pollination success, even if they disagree on the exact nature of the relationship (e.g., see Pleasants 1983, Rathcke 1983, Thomson 1983, Waser 1983). The models we proposed (Table 3 ) reflect one likely possibility: pollination suf- 
TABLE 10. Summary of results of multiple regressions, as in Tables 7-8, but (A) treating all conspecific flowers within $2 \mathrm{~m}$ of the focal plant as CEN and adjusting other independent variables accordingly; or, (B) weighting numbers of flowers used in calculating each independent variable by attractiveness to the hummingbird pollinators of the species being investigated.

(A) Variables calculated assuming CEN to extend to $2 \mathrm{~m}$

Number of times $H_{0}$ rejected with CONGR as dependent variable (compare with Table 7 summary).

Absolute density model

Relative density model

\begin{tabular}{|c|c|c|c|c|c|c|}
\hline & \multirow[b]{2}{*}{ CEN } & \multirow[b]{2}{*}{ DCONS } & \multirow[b]{2}{*}{ DHETS } & \multirow[b]{2}{*}{ CEN } & \multirow[b]{2}{*}{ PRCFL } & \multirow[b]{2}{*}{$\begin{array}{c}\text { DCONS + } \\
\text { DHETS }\end{array}$} \\
\hline & & & & & & \\
\hline Short flowers & 1 & $\begin{array}{l}2 \\
0\end{array}$ & $\begin{array}{l}0 \\
0\end{array}$ & 1 & 2 & 0 \\
\hline
\end{tabular}

Number of times $H_{0}$ rejected with HEGR as dependent variable (compare with Table 8 summary). Absolute density model

\begin{tabular}{|c|c|c|c|c|c|c|c|c|}
\hline & & \multirow[b]{2}{*}{ PRCFL } & \\
\hline & DHETS & CEN & DCONS & $\mathrm{D}$ & & CEN & $\begin{array}{c}\text { DCONS + } \\
\text { DHETS }\end{array}$ & $\mathrm{D}$ \\
\hline Short flowers & 1 & 0 & 0 & 0 & 1 & 0 & 0 & 0 \\
\hline Long flowers & 1 & 0 & 1 & 0 & 2 & 0 & 1 & 0 \\
\hline
\end{tabular}

(B) Variables weighted by flower attractiveness*

Number of times $H_{0}$ rejected with CONGR as dependent variable (compare with Table 7 summary).

Absolute density model

Relative density model

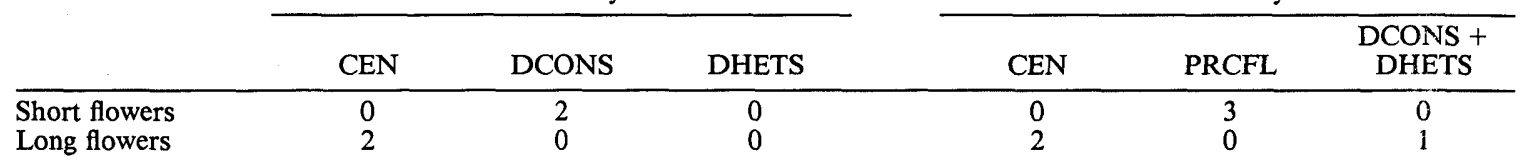

Number of times $H_{0}$ rejected with HEGR as dependent variable (compare with Table 8 summary).

Absolute density model

Relative density model

\begin{tabular}{|c|c|c|c|c|c|c|c|c|}
\hline & & \\
\hline & DHETS & CEN & DCONS & D & PRCFL & CEN & $\begin{array}{c}\text { DCONS + } \\
\text { DHETS }\end{array}$ & D \\
\hline Short flowers & 0 & 0 & 0 & 0 & 1 & 0 & 0 & 0 \\
\hline
\end{tabular}

* $F$ values in Tables 7-8 for CEN and DCONS in the CONGR regressions variables were not altered by this procedure.

fers if flowers are isolated from conspecifics either by distance or by intervening heterospecifics. Although models were not expected to apply equally well to the two plant guilds examined, in both guilds statistical effects of neighboring plants on one another's pollen loads sometimes followed the models, often were negligible, and sometimes strongly contradicted the models. Even within a given plant population, the nature of neighborhood effects changed from month to month (Tables 7 and 8 ). This suggests that many factors, of which the local floral neighborhood is only one, affect the foraging behavior of hummingbirds and the pollen loads they carry. As the low $R^{2}$ values throughout Tables 7 and 8 attest, the myriad other variables undoubtedly confound any role that neighborhood alone might play in determining pollen loads.

\section{Is there a contrast between guilds?}

In the absolute density models (Table 3 ) the number of conspecific grains received (CONGR) was twice a positive function of number of flowers on the central plant (CEN), twice of density of conspecific flowers among neighboring plants (DCONS) (Table 7). Simply put, in some cases more conspecific pollen grains are likely to be received when more conspecific donors are around. In none of the 12 runs, however, did CONGR decrease with increasing absolute density of heterospecific flowers (DHETS). Thus, this set of analyses failed to support consistently the prediction that neighborhoods would affect pollination of short flowers but not long flowers.

Likewise, the guild to which a species belonged had little effect on the relationships between neighborhood and the receipt of heterospecific grains (HEGR) (Table 8). In fact, in both guilds statistical results sometimes contradicted the models presented in Table 3. For example, in three runs HEGR increased, rather than decreased, with increases in DCONS (Table 8). Some of these unexpected results probably arose from the tendency of flowers to receive heterospecific grains together with conspecific grains (Table 10). The number of heterospecific grains received should be independent of the number of conspecific grains received only if pollinators visit frequently and the composition of the floral neighborhood is the predominant influence on pollen loads (see Thomson 1983). Otherwise, as in the case of Razisea (where many flowers received no grains of either variety), those variables that affect receipt of 
conspecific grains are likely to affect receipt of heterospecific grains in the same way.

Only in the relative density model applied to CONGR (Table 7) was there some difference between the two guilds. As Table 7 shows, CONGR increased with increasing relative density of conspecific flowers (PRCFL) in three of six sampling runs on short-flowered plants but none of six runs on long-flowered plants. These results confirm our prediction in part. Nevertheless, even short-flowered plants in this analysis did not always experience neighborhood effects: in the other three runs on Hansteinia and Besleria, relationships between CONGR and PRCFL were nowhere near significance.

\section{Effects of flowering season on pollen loads}

Comparisons among the three sampling runs on each species (Table 5) suggest that absolute and relative density of flowers, in the gross sense, may affect receipt of conspecific pollen, even though no such conclusion can be drawn for receipt of heterospecific grains. In all four species, significantly fewer flowers in the third sampling run received adequate pollen loads than in the second run, when (except for Drymonia) conspecific flowers throughout the cloud forest were more numerous in absolute and relative terms (Fig. 3). Likewise, in both short-flowered species, fewer flowers in the first run received adequate loads than in the second. The absence of significant differences between first and second runs for either long-flowered species (Table 5) could reflect the fact that there was little change in overall flower density between those two runs (Fig. 3). The significant seasonal effects on pollen loads parallel those found in at least one other bird-pollinated plant species (Waser 1978a).

\section{Is variation among pollen loads significant to the plants investigated?}

We chose to examine pollen load, rather than seed set, in order to isolate the effects of pollination from the effects of numerous other variables that can influence seed set (e.g., see Stephenson 1981, Heithaus et al. 1982, McDade and Davidar 1984, Sutherland and Delph 1984). Several authors (e.g., Bawa and Beach 1981, Stephenson 1981) have recently suggested that most flowers in natural populations receive loads of conspecific pollen adequate to fertilize all ovules, such that seed or fruit set is rarely limited by the number of pollen grains received. Even if floral neighborhoods contributed to variance among pollen loads in such populations, the effects on floral fecundity might be slight.

In the four species we examined, however, we found that inadequate loads of conspecific pollen, with fewer grains than the number of ovules, occurred frequently (Table 5). Like other authors (e.g., Schemske et al. 1978, Silander and Primack 1978, Bierzychudek 1981,
Snow 1982, Gross and Werner 1983, McDade 1983, Rathcke 1983, Campbell 1985b, Hainsworth et al. 1985), we infer that fecundity is potentially pollen limited in these species. Any factor significantly influencing the numbers of grains received by the flowers we examined, then, might affect not only offspring quality but also the number of seeds set. Although the relationship between numbers of seeds set and recruitment in the next generation is not simple, it is reasonable to assume that it is positive (Louda 1982, Rathcke 1983). In short, there is likely to be a link between the conspecific pollen loads we observed and the fitness of the plants concerned, at least in terms of female function.

A link may also exist between the number of heterospecific grains received by the plants we examined and floral fecundity or plant fitness (Waser 1978b, Thomson et al. 1981, Rathcke 1983). Numbers of heterospecific grains varied widely within and among the four species. Only a few studies (e.g., Waser 1978a, Brown and Kodric-Brown 1979, Campbell and Motten 1985) document the presence of heterospecific pollen on stigmas in natural populations, and fewer still address its effect on fecundity. Here, the heterospecific loads reported in Table 5 never appeared to restrict access of conspecific grains to the stigmatic surface. We cannot discount, however, the possibility that these grains had more subtle, detrimental effects, such as allelopathy (Sukhada and Jayachandra 1980, Thomson et al. 1981) or, when they germinated, stylar clogging.

\section{Implications to competition and facilitation}

Competition among hummingbird-pollinated neotropical plants is the subject of much debate. The chief point of contention is whether the seasonal dispersion of flowering periods in certain communities is sufficiently nonrandom to be considered as indirect evidence of past competition for pollination (Stiles 1977, Poole and Rathcke 1979, Cole 1981, Gleeson 1981, Rathcke 1984). To our knowledge, no one has clarified or investigated the presumed mechanism for competition, i.e., negative, density-dependent effects of different plant species on one another's pollination.

Among our samples, the evidence for competition is mixed at best. In no case did increases in absolute numbers of neighboring heterospecific flowers lead to significantly decreased conspecific pollen loads (Table 7). Results from the "relative density model" suggest that competition frequently (although not always) does affect pollen loads received by short flowers, but not those received by long flowers. In fact, data in Table 7 suggest that long flowers of different species, like the neotropical gingers (Costus) investigated by Schemske (1981), occasionally have facilitative effects on one another (see also Rathcke 1983, Thomson 1983). In two of six runs, once each for Razisea and Drymonia, increases in density of heterospecific flowers actually led to increased deposition of conspecific grains. These 
facilitative effects were not evident in other runs on those species, however.

Discussions of competition have also suggested a role for heterospecific pollen (e.g., Waser 1978b). Here, though, the lack of consistent density-dependent effects on HEGR (Table 8) suggest that even if high loads of heterospecific grains were to decrease floral fecundity, neighborhood effects would be unlikely to provide consistent directional selection.

The scarcity of evidence in Tables 7 and 8 for strong, consistent competition may result from conflicting effects between heterospecific flowers' role in attracting pollinators to the neighborhood and their contribution to improper pollen transfer once the pollinators are attracted. As Thomson (1983) and Rathcke (1983) point out, interactions between plants in the same guild may shift from facilitation to competition, depending on the relative density of pollinators. The wide range of neighborhoods we examined (Table 4) may have included both situations where heterospecific plants helped to draw in pollinators, and situations where heterospecific plants increased the frequency of improper pollen transfer (cf. Thomson 1983: Fig. 22-2). If heterospecific plants, along with conspecifics, consistently helped to draw in hummingbirds at low flower densities, while contributing to improper pollen transfer at all flower densities, we might expect two results: (1) an increase in total pollen load (CONGR + HEGR, Table 2) with an increase in total flower density (DCONS + DHETS), and (2) an increase in load purity alone (CONGR/[CONGR + HEGR]) with an increase in relative frequency of conspecifics (PRCFL). We examined these possibilities with Spearman rank correlations. (1) Because CONGR usually greatly exceeded HEGR, there were no strong relationships between total pollen load and total flower density beyond those apparent in results for CONGR alone (Table 7). (2) Of the few strong relationships that existed between load purity and neighborhood purity, as many were negative as were positive. We conclude that the species we examined did not experience a straightforward trade-off between competition and facilitation.

Our definition of floral neighborhood doubtless affected the results. The sampling scheme would not have detected effects of densely flowering heterospecifics outside the immediate neighborhood of a focal plant. Furthermore, patterns of interspersion among neighboring flowers might have been more important neighborhood variables than the raw flower totals we used. We cannot assess the possible impact of these factors, but the consistent inconsistency among the results implies that they are an accurate qualitative, if not quantitative, representation of the real complexities of pollination of the species examined.

In short, results reported in Tables 7 and 8 suggest that neither competition for pollination nor facilitation occurs uniformly in either guild of hummingbird-pol- linated plants in the Monteverde cloud forest. There is little support for inferences of competition among bird-pollinated plants at other neotropical sites (e.g., Stiles 1977, 1978, 1981, Feinsinger 1978), especially among bird-pollinated plants with long flowers. Is there any reason to think that our results are unique? Until recently, many studies dealing with flowering phenologies or the flowering structure of plant communities, like those dealing with character displacement among coexisting vertebrates (Simberloff 1983), have simply assumed that competition exists without examining the mechanism. We suspect that careful examinations of the actual effects of neighboring plants on one another's pollination will show that competition sometimes but by no means always exists (cf. Rathcke 1983, Real 1983, Thomson 1983, Campbell 1985a, b), regardless of the geographic location and pollination guild. It is wrong to generalize too widely from our results, coming from two guilds of large, showy flowers having vertebrate pollinators. Nevertheless, it may also be a mistake to generalize too widely from results obtained from dense fields of temperate zone flowers that have generated the convincing experiments, and much of the theory, on competition for pollination and its possible selective effects on flowering phenologies.

\section{ACKNOWLEDGMENTS}

We are especially grateful to three persons whose participation in all phases of the field research was invaluable: W. Z. Pounds, S. Sargent, and J. A. Wolfe. Y. B. Linhart supplied support and expertise throughout the years of the Monteverde research. C. A. Guindon, R. Shuster, and especially J. H. Beach were responsible for many of the 1981-1982 data that served as background to this study. A suggestion made by $S$. C. H. Barrett led to the idea of examining pollen loads on stigmas. R. K. Colwell, D. Hayne, J. G. Saw, and D. R. Strong provided statistical advice. W. Haber and $\mathrm{K}$. A. WinnettMurray provided advice and assistance in the field. Personnel of the Centro Cientifico Tropical, especially J. A. Tosi in San Jose and W. Guindon at Monteverde, facilitated our use of the Monteverde Cloud Forest Reserve. Personnel of the Organization for'TropicalStudies, expecially Roxana Díaz, helped with logistic problems. Plants were determined by W. Judd, K. Perkins, and D. Hall (University of Florida); W. Burger and P. Matekaitis (Field Museum); G. Davidse and R. E. Gereau (Missouri Botanical Garden); L. Skog (U. S. National Museum); and L. H. Durkee (Grinnell College). We thank M. L. Crump, Y. B. Linhart, L. A. McDade, J. A. Pounds, W. Z. Pounds, M. V. Price, and N. M. Waser for comments on earlier drafts, and thank R. W. Cruden, D. W. Schemske, and J. D. Thomson for detailed reviews. The study was supported by NSF grants DEB $80-11008$ to Feinsinger and DEB 80 11023 to Y. B. Linhart.

\section{LITERATURE CITED}

Augspurger, C. A. 1980. Mass-flowering of a tropical shrub (Hybanthus prunifolius): influence on pollinator attraction and movement. Evolution 34:475-488.

. 1981. Reproductive synchrony of a tropical shrub: experimental studies on effects of pollinators and seed predators on Hybanthus prunifolius (Violaceae). Ecology 62: 775-788.

Bawa, K. S., and J. H. Beach. 1981. Evolution of sexual 
systems in flowering plants. Annals of the Missouri Botanical Garden 68:254-274.

Bertin, R. I. 1982. Paternity and fruit production in trumpet creeper (Campsis radicans). American Naturalist 119:694709.

Bierzychudek, P. 1981. Pollinator limitation of plant reproductive effort. American Naturalist 117:838-840.

Bobisud, L. B., and R. J. Neuhaus. 1975. Pollinator constancy and survival of rare species. Oecologia (Berlin) 21: 263-272.

Brown, J. H., and A. Kodric-Brown. 1979. Convergence, competition, and mimicry in a temperate community of hummingbird-pollinated flowers. Ecology 60:1022-1035.

Campbell, D. R. 1985a. Pollen and gene dispersal: the influences of competition for pollination. Evolution 39:418431.

- 1985b. Pollinator sharing and seed set of Stellaria pubera: competition for pollination. Ecology 66:544-553.

Campbell, D. R., and A. F. Motten. 1985. The mechanism of competition for pollination between two forest herbs. Ecology 66:554-563.

Cole, B. J. 1981. Overlap, regularity, and flowering phenologies. American Naturalist 117:993-997.

Connor, E. F., and D. Simberloff. 1978. Species number and compositional similarity of the Galapagos flora and avifauna. Ecological Monographs 48:219-248.

Cruden, R. W. 1977. Pollen-ovule ratios: a conservative indicator of breeding systems in flowering plants. Evolution 31:32-46.

Evans, E. W. 1983. The influence of neighboring hosts on colonization of prairie milkweeds by a seed-feeding bug. Ecology 64: 648-653.

Feinsinger, P. 1976. Organization of a tropical guild of nectarivorous birds. Ecological Monographs 46:257-291.

-1978. Ecological interactions between plants and hummingbirds in a successional tropical community. Ecological Monographs 48:269-287.

- 1983. Coevolution and pollination. Pages 282-310 in D. J. Futuyma and M. Slatkin, editors. Coevolution. Sinauer, Sunderland, Massachusetts, USA.

Feinsinger, P., and R. K. Colwell. 1978. Community organization among neotropical nectar-feeding birds. American Zoologist 18:779-795.

Gleeson, S. K. 1981. Character displacement in flowering phenologies. Oecologia (Berlin) 51: 294-295.

Gross, R. S., and P. A. Werner. 1983. Relationships among flowering phenology, insect visitors, and seed-set of individuals: experimental studies on four co-occurring species of goldenrod (Solidago: Compositae). Ecological Monographs 53:95-117.

Hainsworth, F. R., L. L. Wolf, and T. Mercier. 1985. Pollen limitation in a monocarpic species, Ipomopsis aggregata. Journal of Ecology 73:263-270.

Heithaus, E. R., E. Stashko, and P. K. Anderson. 1982. Cumulative effects of plant-animal interactions on seed production by Bauhinia ungulata, a neotropical legume. Ecology 63:1294-1302.

Holdridge, L. R. 1967. Life zone ecology. Tropical Science Center, San Jose, Costa Rica.

Lawton, R., and V. Dryer. 1980. The vegetation of the Monteverde Cloud Forest Reserve. Brenesia 18:101-116.

Levin, D. A., and W. W. Anderson. 1970. Competition for pollinators between simultaneously flowering species. American Naturalist 104:455-467.

Linhart, Y. B. 1973. Ecological and behavioral determinants of pollen dispersal in hummingbird-pollinated Heliconia. American Naturalist 107:511-523.

Louda, S. M. 1982. Distribution ecology: variation in plant recruitment over a gradient in relation to insect seed predation. Ecological Monographs 52:25-41.

Manasse, R. S., and H. F. Howe. 1983. Competition for dispersal agents among tropical trees: influences of neighbors. Oecologia (Berlin) 59:185-190.

Martin, F. W. 1959. Staining and observing pollen tubes in the style by means of fluorescence. Stain Technology 34: 125-128.

McDade, L. A. 1983. Pollination intensity and seed set in Tricanthera gigantea (Acanthaceae). Biotropica 15:122-124.

McDade, L. A., and P. Davidar. 1984. Determinants of fruit and seed set in Pavonia dasypetala (Malvaceae). Oecologia (Berlin) 64:61-67.

Mulcahy, D. 1983. Models of pollen tube competition in Geranium maculatum. Pages 151-161 in L. A. Real, editor. Pollination biology. Academic Press, New York, New York, USA.

Mulcahy, D. L., P. S. Curtis, and A. A. Snow. 1983. Pollen competition in a natural population. Pages 330-337 in C. E. Jones and R. J. Little, editors. Handbook of experimental pollination biology. Van Nostrand Reinhold, New York, New York, USA.

Mulcahy, D. L., and G. B. Mulcahy. 1983. Pollen selection: an overview. Pages 15-17 in D. L. Mulcahy and E. Ottaviano, editors. Pollen: biology and implications for plant breeding. Elsevier, Amsterdam, The Netherlands.

Pleasants, J. M. 1983. Structure of plant and pollinator communities. Pages 375-393 in C. E. Jones and R. J. Little, editors. Handbook of experimental pollination biology. Van Nostrand Reinhold, New York, New York, USA.

Poole, R. W., and B. J. Rathcke. 1979. Regularity, randomness, and aggregation in flowering phenologies. Science 203: $470-471$.

Rathcke, B. 1983. Competition and facilitation among plants for pollination. Pages 305-329 in L. A. Real, editor. Pollination biology. Academic Press, New York, New York, USA.

ㄴ. 1984. Patterns of flowering phenologies: testability and causal inference using a random model. Pages 383393 in D. R. Strong, D. Simberloff, L. G. Abele, and A. B. Thistle, editors. Ecological communities: conceptual issues and the evidence. Princeton University Press, Princeton, New Jersey, USA.

Real, L. A. 1983. Microbehavior and macrostructure in pollinator-plant interactions. Pages 287-304 in L. A. Real, editor. Pollination biology. Academic Press, New York, New York, USA.

Rohlf, F. J., and R. R. Sokal. 1969. Statistical tables. Freeman, San Francisco, California, USA.

Schemske, D. W. 1981. Floral convergence and pollinator sharing in two bee-pollinated tropical herbs. Ecology 62: 946-954.

Schemske, D. W., and L. P. Pautler. 1984. The effects of pollen composition on fitness components in a neotropical herb. Oecologia (Berlin) 62:31-36.

Schemske, D. W., M. F. Willson, M. N. Melampy, L. J. Miller, L. Verner, K. M. Schemske, and L. B. Best. 1978. Flowering ecology of some spring woodland herbs. Ecology 59: 351-366.

Silander, J. A., and R. B. Primack. 1978. Pollination intensity and seed set in the evening primrose (Oenothera fruticosa). American Midland Naturalist 100:213-216.

Simberloff, D. 1983. Sizes of coexisting species. Pages 404430 in D. J. Futuyma and M. Slatkin, editors. Coevolution. Sinauer, Sunderland, Massachusetts, USA.

Snow, A. A. 1982. Pollination intensity and potential seed set in Passiflora vitifolia. Oecologia (Berlin) 55:231-237.

Steel, R. G. D., and J. H. Torrie. 1960. Principles and pro- 
cedures of statistics. McGraw-Hill, New York, New York, USA.

Stephenson, A. G. 1981. Flower and fruit abortion: proximate causes and ultimate functions. Annual Review of Ecology and Systematics 12:253-279.

Stiles, F. G. 1975. Ecology, flowering phenology, and hummingbird pollination of some Costa Rican Heliconia species. Ecology 56:285-301.

- 1977. Coadapted competitors: the flowering seasons of hummingbird-pollinated plants in a tropical forest. Science 198:1177-1178.

- 1978. Temporal organization of flowering among the hummingbird food-plants of a tropical wet forest. Biotropica 10:194-210.

-1 1981. Geographical aspects of the bird-flower coevolution, with particular reference to Central America. Annals of the Missouri Botanical Garden 68:323-351.

Straw, R. M. 1972. A Markov model for pollinator constancy and competition. American Naturalist 102:597-621.

Sukhada, K., and Jayachandra. 1980. Pollen allelopathya new phenomenon. New Phytologist 84:739-746.

Sutherland, S., and L. F. Delph. 1984. On the importance of male fitness in plants: patterns of fruit-set. Ecology 65: 1093-1104.
Thomson, J. D. 1983. Component analysis of communitylevel interactions in pollination systems. Pages 451-460 in C. E. Jones and R. J. Little, editors. Handbook of experimental pollination biology. Van Nostrand Reinhold, New York, New York, USA.

Thomson, J. D., B. J. Andrews, and R. C. Plowright. 1981. The effect of a foreign pollen on ovule development in Diervilla lonicera (Caprifoliaceae). New Phytologist 90:777783.

Waser, N. M. 1978a. Competition for hummingbird pollination and sequential flowering in two Colorado wildflowers. Ecology 59:934-944.

$1978 \mathrm{~b}$. Interspecific pollen transfer and competition between co-occurring plant species. Oecologia (Berlin) 36: 223-236.

1983. Competition for pollination and floral character differences among sympatric plant species: a review of evidence. Pages 277-293 in C. E. Jones and R. J. Little, editors. Handbook of experimental pollination biology. Van Nostrand Reinhold, New York, New York, USA.

Wissel, C. 1977. On the advantage of the specialization of flowers on particular pollinator species. Journal of Theoretical Biology 69:11-22. 